\title{
MODIFICATION OF C AND N SOURCES FOR ENHANCED PRODUCTION OF CYCLOSPORIN 'A' BY ASPERGILLUS TERREUS
}

\author{
Sundas Tanseer, Tehmina Anjum*
}

Institute of Mycology \& Plant Pathology, University of the Punjab, Lahore, Pakistan.

Submitted: August 12, 2010; Returned to authors for corrections: December 22, 2010; Approved: May 30, 2011.

\begin{abstract}
Most of the studies regarding cyclosporin 'A' production through fungi concentrate around Tolypocladium inflatum. This is mainly due to lower reported production of this drug in other fungi. The present study was therefore conducted to explore indigenous isolates of Aspergillus terreus for synthesis of this drug and defining a production medium for obtaining high yield of cyclosporin 'A'. For this purpose carbon and nitrogen sources were optimized for the selected best strain of $A$. terreus. Overall results depicted that the best cyclosporin 'A' yield from selected Aspergillus terreus (FCBP58) could be obtained by using production medium containing glucose $10 \%$ as carbon source and peptone $0.5 \%$ as nitrogen source. This modification in production medium enhanced drug synthesis by selected fungi significantly. The production capabilities when compared with biomass of fungi there was found no relationship between the two confirming that the medium modification increased overall drug synthesis powers of the fungi.
\end{abstract}

Key words: Aspergillus terreus, cyclosporin 'A', carbon, nitrogen.

\section{INTRODUCTION}

Secondary metabolites of filamentous fungi are of extreme interest to humankind due to their pharmaceutical and/or toxic properties (6). Cyclosporin ' $A$ ' is a main product of secondary metabolism of fungal species originally identified as strains of Trichoderma polysporum (12) but currently classified as belonging to the species Tolypocladium inflatum. Other soil inhabiting filamentous fungi like Fusarium solani (26) Neocosmospora vasinfecta (24) and Fusarium oxysporum (13) have also been reported to produce lower levels of cyclosporins. Recently, different strains of $A$. terreus have been identified as new producers of cyclosporine 'A' $(27,28)$.

Cyclosporin ' $\mathrm{A}$ ' is a nonpolar cyclic peptide of eleven amino acids with a molecular weight of 1202.6. It exhibits a narrow spectrum of antifungal activity and in addition has immunosuppressant properties (12). This is a strong and selective immunosuppressant in transplant surgery inhibiting the rejection of allogeneic grafts and is also a very promising drug against autoimmune and parasitic diseases (8). In addition this is applied in reversing multidrug resistance in several types of cancers (11).

*Corresponding Author. Mailing address: Institute of Mycology \& Plant Pathology, Quaid-e-Azam Campus, University of the Punjab, Lahore-54590, Pakistan.; Tel.: +92-333-4383875 Fax: +92-42-9231187.; E-mail: anjum@mpp.pu.edu.pk / tehminaanjum@yahoo.com 
The drug is produced by submerged culturing of aerobic filamentous fungi (17). Workers have also isolated the enzyme fraction from $T$. inflatum extracts $(5,18)$. Fermentation conditions (21) and nutrient medium have already been optimized for the production of cyclosporin 'A' by T. inflatum. Some workers obtained best production of the drug from $T$. inflatum by exploiting sorbose in their fermentation media (2, 15) while others found glucose and yeast extract to be best carbon and nitrogen sources (16). Investigation by Sallam et al. (28) for cyclosporin ' $A$ ' production by $A$. terreus revealed that glucose, bactopeptone, $\mathrm{pH} 5.3$ incubated with $2 \%$ standard inoculum of 48 hour age, shaken at $200 \mathrm{rpm}$ for 10 days are the best fermentation condition.

Cyclosporin ' $A$ ' production was significantly influenced by the addition of amino acids $(16,19)$. The external addition of L-leucine and L-valine during exponential growth phase highly increased the production of cyclosporin ' $A$ ' $(1,3)$. The productivity from $T$. inflatum was markedly increased by utilizing immobilized fungus $(20,22)$ in the presence of Lvaline $(9,10)$. Sallam et al. (27) investigated the formation of cyclosporin ' $A$ ' by immobilizing the spores and mycelium of A. terreus and found L-valine to increase the production. The current study is conducted to detect high yielding strains of $A$. terreus among several local isolates and enhance the production powers of local isolate by altering carbon and nitrogen sources in nutritional medium.

\section{MATERIALS AND METHODS}

\section{Procurement of fungal strains}

Nine strains of $A$. terreus were obtained from the First Fungal Culture Bank of Pakistan (FCBP). The strains were preserved on Malt Extract Agar (MEA) at $4{ }^{\circ} \mathrm{C}$ and were provided in the form of slants in culture tubes. The strains were revived on MEA plates (malt extract $2 \%$, agar $2 \%, \mathrm{pH} 6.5$ ) and the inoculated plates were incubated at $27 \pm 1{ }^{\circ} \mathrm{C}$ for $4-5$ days. The strain numbers and their origins of isolation are mentioned in Table 1.

Table 1. Aspergillus terreus strain numbers and their origin of isolation.

\begin{tabular}{ll}
\hline Strain no. & Origin of isolation \\
\hline FCBP58 & Soil, canal bank Lahore \\
FCBP113 & Air mycoflora, NIAB \\
FCBP119 & Air microflora, Punjab university Lahore. \\
FCBP122 & Dalbergia sissoo root \\
FCBP148 & Air microflora, Punjab university Lahore \\
FCBP168 & Air microflora, Punjab university Lahore \\
FCBP196 & Air microflora, Punjab university Lahore \\
FCBP536 & Air microflora, Punjab university Lahore \\
FCBP652 & Soil, Lahore \\
\hline
\end{tabular}

\section{Seed inoculum preparation}

Seed inoculum was prepared in Malt Yeast extract (MY) medium (malt extract $2 \%$, yeast extract $0.4 \%$, initial $\mathrm{pH}$ of 5.7). A $0.8 \mathrm{~cm}$ disk of five days old strain culture was inoculated in sterilized medium and incubated on orbital shaker at $200 \mathrm{rpm}$ for 72 hours at $30 \pm 2{ }^{\circ} \mathrm{C}(7)$.

\section{Cultivation}

According to the method of Agathos et al. (2) the flasks containing $50 \mathrm{~mL}$ of production medium (glucose $5 \%$, peptone $1 \%, \mathrm{KH}_{2} \mathrm{PO}_{4} 0.5 \%, \mathrm{KCl} 0.25 \%, \mathrm{pH} 5.3$ as designed by Sallam et al. (28) were inoculated with $5 \mathrm{~mL}$ of prepared seed inoculum (i.e. $10 \% \mathrm{v} / \mathrm{v})$. The inoculated flasks were incubated on orbital shaker at $200 \mathrm{rpm}$ at $30 \pm 2{ }^{\circ} \mathrm{C}$ for 10 days.

\section{Extraction of cyclosporin ' $A$ '}

The extraction of cyclosporin 'A' was performed by using n-butyl in equal quantity in the medium and flasks were incubated at $200 \mathrm{rpm}$ and $30 \pm 2{ }^{\circ} \mathrm{C}$ for 24 hours. Two distinguish immiscible layers of top organic phase and bottom aqueous phase were formed containing extraction solution and medium respectively. The organic phase was carefully separated by using separating funnel and evaporated under 
vacuum till dryness at $40{ }^{\circ} \mathrm{C}$. The dried sample was weighed and dissolved in $30 \mathrm{~mL}$ methanol.

\section{Biomass harvest}

The biomass was harvested by filtering aqueous layer of cultivation medium containing fungal pellets using Whatman filter paper No.1. The biomass was dried in oven overnight at $40{ }^{\circ} \mathrm{C}$ and was weighed.

\section{Analysis and Estimation of cyclosporin ' $A$ '}

Antifungal bioassay: The antifungal bioassay was performed against Aspergillus niger FCBP74 isolated from air mycoflora, Punjab University, Lahore by well method. The inhibition zone was measured by measuring diameter from eight different sides and taking the mean.

High performance liquid chromatography (HPLC): High performance liquid chromatography (HPLC) was done for detection and estimation of cyclosporin 'A'. Hitachi HPLC system equipped with UV-VIS detector (L-2420) and pump (L2130) was used for detection and estimation of cyclosporine ' $A$ ' under the following operating conditions: Mobile phase consisted of acetonitrile: methanol: water (42.5: 20: 37.5), Flow rate of $0.8 \mathrm{~mL} / \mathrm{min}, \mathrm{C}_{18}$ column, wavelength of $215 \mathrm{~nm}$. $20 \mu \mathrm{l}$ of diluted samples and standard samples were injected in the HPLC system. The standards were $100 \mathrm{mg}$ capsules of Sandimmun Neoral ${ }^{\circledR}$ (Novartis) and $\geq 98.5 \%$ pure authentic sample of cyclosporin 'A' purchased from Fluka Analytical, Japan. The following formula was used to determine cyclosporin 'A' level in crude extracts (23).

\% cyclosporin 'A' by weight $=\frac{\mathbf{A}_{\mathbf{s}} \mathbf{W}_{\mathbf{r}} \mathbf{V}_{\mathbf{s}}}{\mathbf{A}_{\mathbf{r}} \mathbf{W}_{\mathbf{s}} \mathbf{V}_{\mathbf{r}}} \times \mathbf{1 0 0}$

Where, As is peak area of sample, Ar is peak area of reference, $\mathrm{Wr}$ is weight of reference material in grams, Ws is weight of sample in grams, $\mathrm{Vs}$ is volume of sample, $\mathrm{Vr}$ is volume of reference material. The areas of sample peaks and of reference peak were calculated from the chromatograms obtained by HPLC program LaChrom Elite.

\section{Optimization of medium composition}

The selected $A$. terreus FCBP58 strain was grown on different medium to achieve an increased yield of cyclosporin 'A'. Previously used cultivation medium containing glucose 5 $\%$, peptone $1 \%, \mathrm{KH}_{2} \mathrm{PO}_{4} 0.5 \%, \mathrm{KCl} 0.25 \%$ and initial $\mathrm{pH}$ of 5.3 as designed by Sallam et al. 2003 was altered by using different carbon and nitrogen sources.

Three sets of media were tested for production of cyclosporin 'A'. In the first set, six carbon sources i.e. glycerol, glucose, maltose, fructose, sucrose and cellulose were used in four different concentrations of $1,2,5$ and $10 \%(w / v)$ in replacement of glucose $5 \%$. In the second set of production medium, Peptone, trypton and casamino acids in concentrations of $0.5,1.0,1.5$ and $2.0 \%(\mathrm{w} / \mathrm{v})$ were used in place of peptone $1 \%$. Four different amino acids (asparagine, tyrosine, valine and leucine) in concentrations of $0.1,0.2,0.4$ and $0.6 \%(\mathrm{w} / \mathrm{v})$ were supplemented to the medium in the third set.

A $5 \mathrm{~mL}$ of prepared seed inoculum was inoculated in the prepared cultivate media of different sets and incubated on orbital shaker at $200 \mathrm{rpm}$ and $30 \pm 2{ }^{\circ} \mathrm{C}$ for 10 days. The extraction, analysis and estimation of cyclosporin ' $A$ ' was performed by the same procedure as described above for the selection of best yielding strain.

\section{RESULTS AND DISCUSSION}

\section{Screening of fungal strains}

Present study was conducted to design a production media most conducive for cyclosporin 'A' production using $A$. terreus strain. In the first step nine isolates of the selected fungal species were checked for the drug production. The strains isolated from soil i.e., FCBP652, FCBP122 and FCBP58 
produced maximum quantities of cyclosporin ' $A$ '. The highest production reached to $62.4 \mu \mathrm{g} / \mathrm{mL}$ by FCBP58 (Fig. 1) as shown in Table 2. This quantity was much lower than $105.5 \mathrm{mg} / \mathrm{L}$ recorded by Dreyfuss et al. (12) and Agathos et al. (2), and $183 \mathrm{mg} / \mathrm{L}$ recorded by Balakrishan and Pandey, (3) by most studied fungal strain T. inflatum. Sallam et al. (28) also recorded higher productivity of $86.57 \mathrm{mg} / \mathrm{L}$ by an isolate of $A$. terreus. The project was therefore planned to enhance the production potential of FCBP58 for increased drug production.

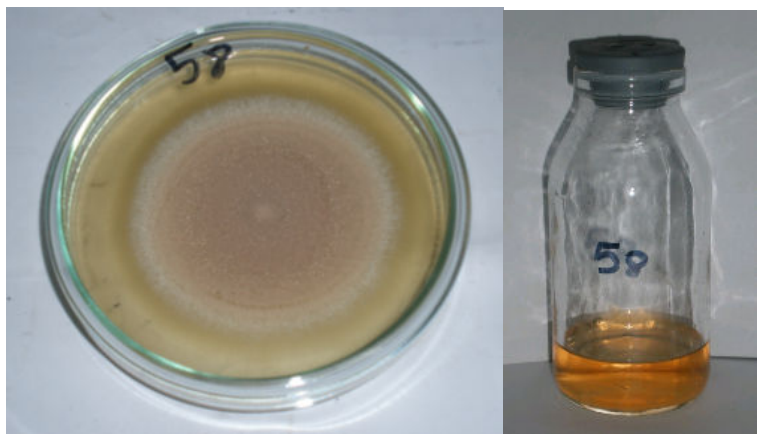

Figure 1. Culture of indigenous strain of Aspergillus terreus FCBP58 (left) and harvested mixture from Aspergillus terreus FCBP58 (right).

Table 2. Cyclosporin 'A' production by nine different Aspergillus terreus strains.

\begin{tabular}{lccccc}
\hline \multicolumn{1}{c}{ Strains } & Peak area & dry weight & \% Cyclosporin & wt. of & wt. of \\
\hline FCBP58 & $9,585,692$ & 32 & 9.76 & 3.12 & $* 62.4 \pm 2.89$ \\
FCBP113 & $5,190,782$ & 22 & 7.69 & 1.69 & $33.38 \pm 1.16$ \\
FCBP119 & $1,290,593$ & 36 & 1.13 & 0.30 & $6.0 \pm 1.85$ \\
FCBP122 & $8,447,103$ & 25 & 11.04 & 2.76 & $55.2 \pm 2.6$ \\
FCBP148 & $8,586,308$ & 27 & 10.43 & 2.81 & $56.2 \pm 1.85$ \\
FCBP168 & $5,031,317$ & 33 & 4.95 & 1.63 & $32.6 \pm 1.5$ \\
FCBP196 & $2,327,129$ & 27 & 2.77 & 0.74 & $14.80 \pm 0.75$ \\
FCBP536 & $6,042,242$ & 40 & 4.95 & 1.98 & $39.60 \pm 2.08$ \\
FCBP652 & $7,857,211$ & 30 & 8.51 & 2.55 & $51 \pm 1.74$ \\
\hline
\end{tabular}

\section{Confirmation of cyclosporin ' $A$ '}

Cyclosporin-related metabolites are reported to have a broad spectrum of antifungal activity and a narrow spectrum of activity against bacterial cultures (25). The harvested mixture assumed to have cyclosporins showed strong antifungal activity against $A$. niger when tested through well method. The inhibition zone of restricted growth of $A$. niger was $1.15 \mathrm{~cm}$ (Fig. 2).

When run through HPLC, a peak appeared between 2.7 and $2.8 \mathrm{~min}$ (Fig. 5), which was confirmed as cyclosporin ' $\mathrm{A}$ ' when compared with Sandimmun Neoral ${ }^{\circledR}$ capsules containing $100 \mathrm{mg}$ cyclosporin ' $\mathrm{A}$ ' as active ingredient and pure cyclosporine ' $\mathrm{A}$ ' as authentic drug supplied by Fluka analytical, Japan. Sandimmun Neoral ${ }^{\circledR}$ capsules showed a clear peak at 2.768 min (Fig. 3) whereas authentic compound recorded at $2.81 \mathrm{~min}$ (Fig. 4).

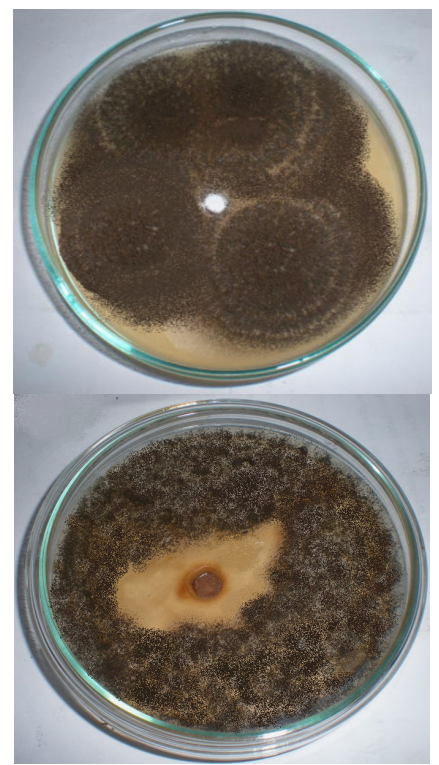

Figure 2. Antifungal activity bioassay of cyclosporin 'A' against Aspergillus niger. Control of Aspergillus niger without extracted liquid (right). Inhibition zone of Aspergillus niger treated with extracted liquid of cyclosporin like compounds. 


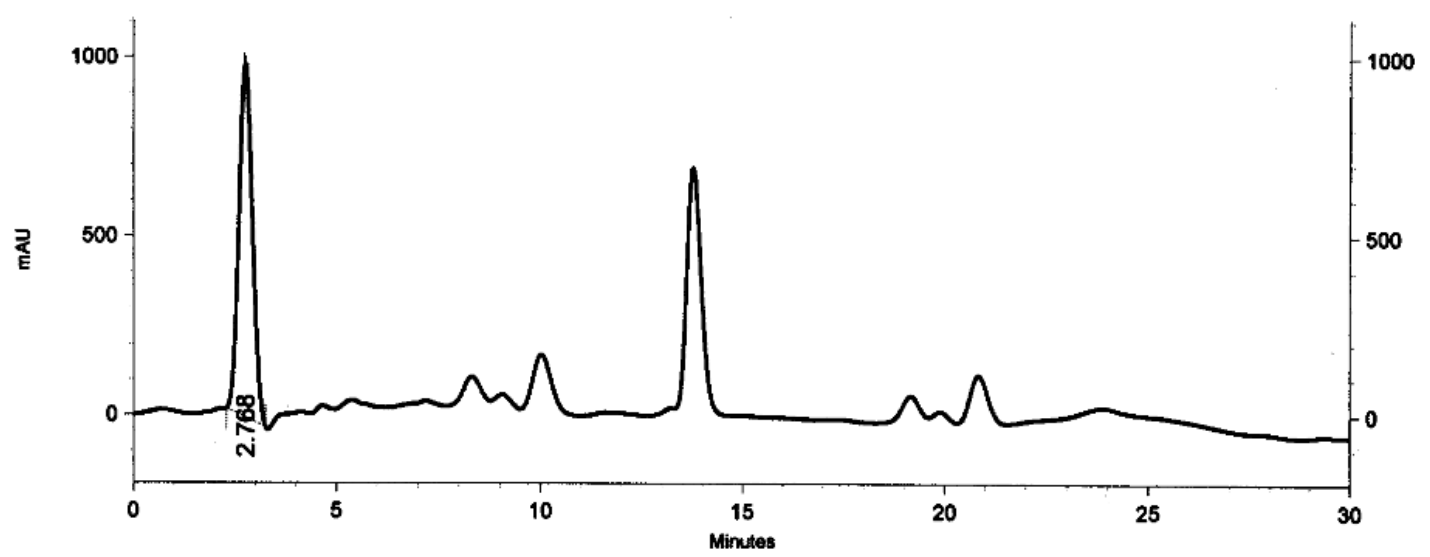

Figure 3. HPLC chromatogram of Sandimmun Neoral ${ }^{\circledR}$ capsule (Novartis) $100 \mathrm{mg}$ cyclosporin as active ingredient extracted at $215 \mathrm{~nm}$. Peak at $2.7 \mathrm{~min}$ is of cyclosporin ' $\mathrm{A}$ '.

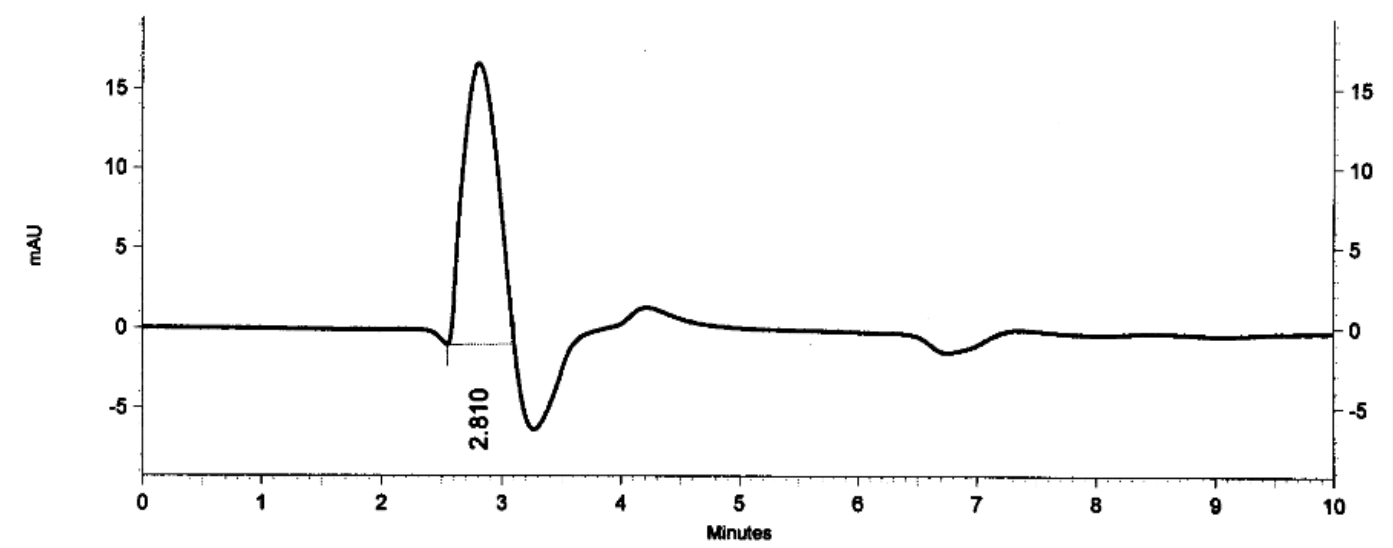

Figure 4. HPLC chromatogram of authentic cyclosporin 'A' purchased from Fluka analytical, Japan. The chromatogram extracted at $215 \mathrm{~nm}$ is showing cyclosporin ' $A$ ' peak at $2.8 \mathrm{~min}$.
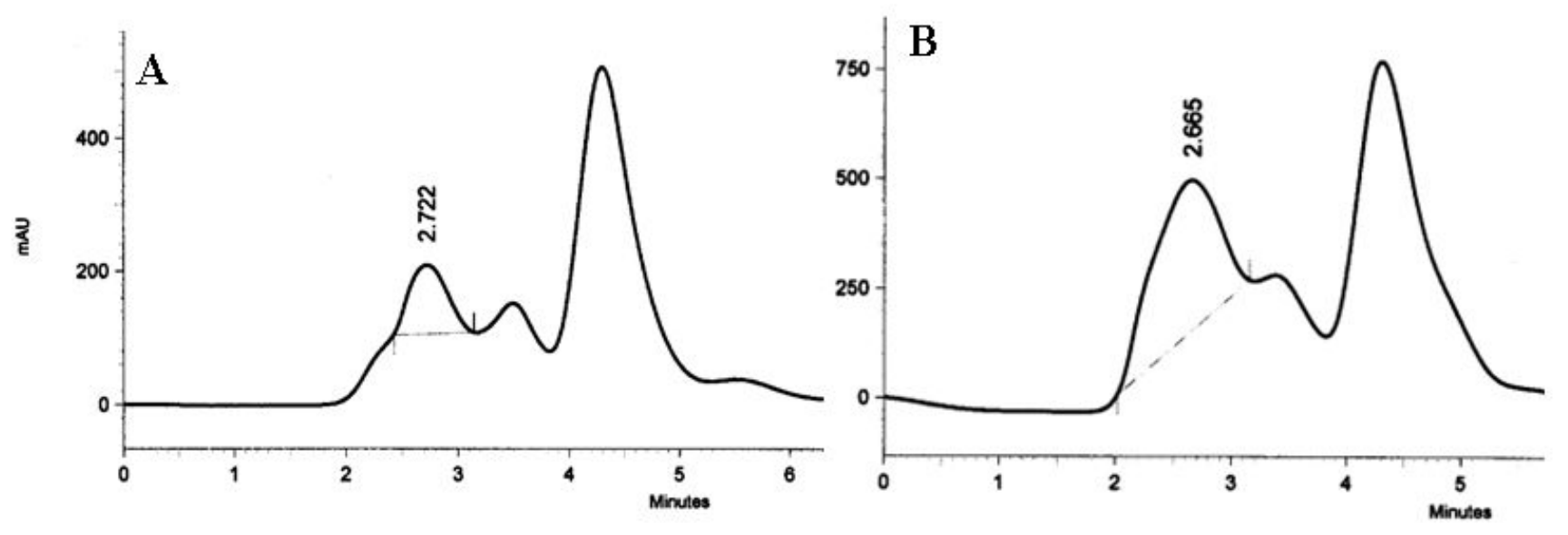


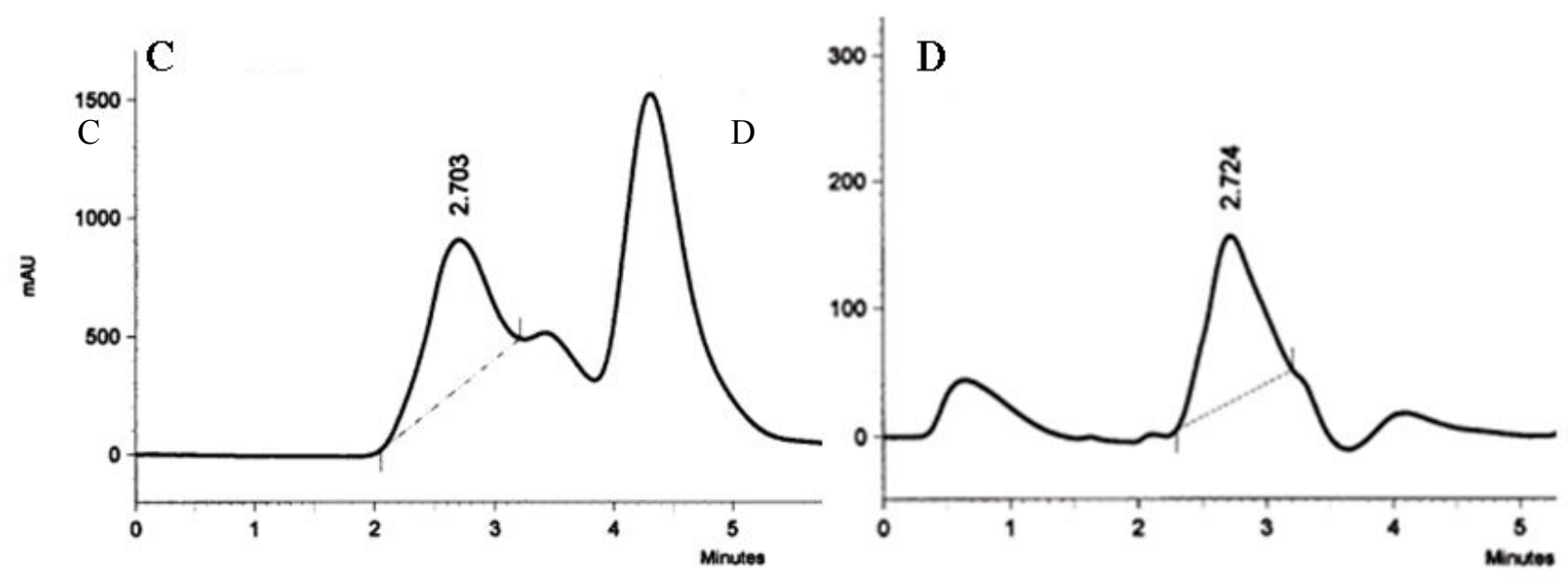

Figure 5. HPLC chromatograms of metabolites from selected strains of Aspergillus terreus. The peak appearing between 2.7-2.8 minutes in chromatograms extracted at $215 \mathrm{~nm}$ has been identified as cyclosporin 'A' where as A: FCBP58; B: Glucose 10\%; C: Peptone $0.5 \%$; D: Valine $0.1 \%$.

\section{Effect of carbon source}

Six different carbon sources were tried in this study to augment the drug production (Table 3). Highest tested concentration was $10 \%$ at which when glucose was added, it proved to be the most effective carbon source significantly increasing cyclosporin 'A' production up to $358.5 \mu \mathrm{g} / \mathrm{mL}$ (Fig. 5B). This shows that A. terreus can utilize this sugar most efficiently as primary source as it is a hexose monosaccharide and is a primary source of energy for most of the living organisms including fungi. Balakrishnan and Pandey (3) stated that by using $T$. inflatum the best yield of cyclosporin 'A' can be obtained on a medium consisting of $20 \mathrm{~g} / \mathrm{L}$ glucose. In a contemporary study Balaraman and Mathew (4) obtained maximum cyclosporin 'A' production with medium containing $8 \%$ glucose. In a research conducted by Sallam et al. (28) on A. terreus, the medium containing $50 \mathrm{~g} / \mathrm{L}$ glucose produced a maximum yield ( $86.77 \mathrm{mg} / \mathrm{L})$ of cyclosporin 'A'.

Beside glucose, cellulose also proved a fairly good carbon source in case of $A$. terreus, when used in concentration of 2 $\%$, it increased cyclosporin ' $\mathrm{A}$ ' production from $62.4 \mu \mathrm{g} / \mathrm{mL}$ to $235 \mu \mathrm{g} / \mathrm{mL}$ (Table 3 ). Increase in concentration to $5 \%$ result in
$143.6 \%$ increase in cyclosporin ' $A$ ' production. However it was lower in comparison to the treatment in which cellulose 2 $\%$ was used. Although cellulose is a complex carbohydrate (polysaccharide), but $A$. terreus is known to produce extracellular endo- $\beta$-1, 4-glucanase, exo- $\beta-1$, 4-glucanase with high levels of $\beta$ - glucosidase and has the ability to utilize cellulose as carbon source. Previous studies also show increase in fungal biomass with increase of carbon sources (29).

\section{Effect of nitrogen sources}

Peptone, trypton and casamino acids was used individually and then in combinations to check the productivity of cyclosporin 'A' (Table 4). These three compounds are amino acid mixtures. Peptone when checked at lower concentration of $0.5 \%$, increased drug production spectacularly by $765.4 \%$ (Fig 5C). Peptones are derived from animal milk or meat digested by proteolytic digestion and contains small peptides along with fats, metals, salts, vitamins and many other biological compounds. As peptone can provide vitamins and metals along with amino acids it proved best supplement for drug enhancement in comparison to others. 
Table 3. Effect of different carbon sources and their concentrations on the production of cyclosporin 'A' by Aspergillus terreus FCBP58.

\begin{tabular}{|c|c|c|c|c|c|c|c|c|}
\hline \multirow[b]{2}{*}{ Treatment } & \multirow[b]{2}{*}{ Peak area } & \multirow[b]{2}{*}{$\begin{array}{c}\text { Weight of dry } \\
\text { biomass } \\
(\mathrm{g} / \mathbf{5 0 m L})\end{array}$} & \multirow[b]{2}{*}{$\begin{array}{c}\text { Weight of dry } \\
\text { extract } \\
(\mathrm{mg} / \mathbf{5 0 m L})\end{array}$} & \multicolumn{5}{|c|}{ Cyclosporin 'A' productivity } \\
\hline & & & & $\%$ & $\mathrm{mg} / 50 \mathrm{~mL}$ & $\mu \mathrm{g} / \mathrm{mL}$ & $\begin{array}{c}\text { Increase/ } \\
\text { decrease in } \\
\text { production }\end{array}$ & $\begin{array}{l}\% \text { increase/ } \\
\text { decrease in } \\
\text { production }\end{array}$ \\
\hline Cellulose $1 \%$ & 666,767 & 0.66 & 53 & 0.41 & 0.22 & $4.40 \pm 0.6$ & -58 & -93.0 \\
\hline Cellulose $2 \%$ & $35,686,578$ & 0.97 & 50 & 23.52 & 11.76 & $235.0 \pm 4.6$ & 172.6 & 276.6 \\
\hline Cellulose $5 \%$ & $23,291,007$ & 2.07 & 55 & 13.82 & 7.60 & $152.0 \pm 2.9$ & 89.6 & 143.6 \\
\hline Cellulose $10 \%$ & $1,197,291$ & 4.81 & 14 & 2.78 & 0.39 & $7.8 \pm 0.5$ & -54.6 & -87.5 \\
\hline Fructose $1 \%$ & 836,205 & 0.23 & 37 & 0.73 & 0.27 & $5.4 \pm 0.5$ & -57.0 & -91.3 \\
\hline Fructose $2 \%$ & $1,315,461$ & 0.33 & 37 & 1.13 & 0.42 & $8.4 \pm 0.6$ & -54.0 & -86.5 \\
\hline Fructose $5 \%$ & $4,616,043$ & 0.86 & 64 & 2.34 & 1.50 & $30.0 \pm 1.7$ & -32.4 & -51.9 \\
\hline Fructose $10 \%$ & $3,727,318$ & 0.93 & 67 & 1.68 & 1.126 & $22.52 \pm 0.8$ & -39.8 & -63.9 \\
\hline Glucose $1 \%$ & $5,562,128$ & 0.26 & 17 & 10.76 & 1.83 & $36.6 \pm 1.2$ & -25.9 & -41.3 \\
\hline Glucose $2 \%$ & $3,047,128$ & 0.45 & 42 & 2.4 & 1.008 & $20.16 \pm 0.7$ & -42.24 & -67.7 \\
\hline Glucose $5 \%$ & $8,076,613$ & 0.84 & 49 & 5.38 & 2.63 & $52.60 \pm 2.0$ & -9.8 & -15.70 \\
\hline Glucose $10 \%$ & $54,475,949$ & 1.18 & 49 & 36.59 & 17.9 & $358.50 \pm 7.5$ & 296.1 & 473.71 \\
\hline Glycerol 1\% & $1,496,101$ & 0.28 & 52 & 0.92 & 0.47 & $9.56 \pm 0.7$ & -52.84 & -84.7 \\
\hline Glycerol 2\% & $1,884,342$ & 0.44 & 53 & 1.128 & 0.59 & $11.80 \pm 1.9$ & -50.6 & -81.08 \\
\hline Glycerol 5\% & $7,103,458$ & 0.78 & 82 & 2.83 & 2.32 & $46.40 \pm 2.9$ & -16.0 & -25.64 \\
\hline Glycerol 10\% & $3,146,050$ & 0.92 & 73 & 1.40 & 1.022 & $20.40 \pm 1.3$ & -42.0 & -67.30 \\
\hline Maltose $1 \%$ & $1,908,806$ & 0.25 & 33 & 1.8 & 0.59 & $11.88 \pm 0.5$ & -50.5 & -81.0 \\
\hline Maltose $2 \%$ & 791,223 & 0.43 & 50 & 0.52 & 0.26 & $5.20 \pm 0.8$ & -57.2 & -91.7 \\
\hline Maltose $5 \%$ & $2,581,235$ & 0.89 & 111 & 0.764 & 0.84 & $16.80 \pm 1.2$ & -45.6 & -73.1 \\
\hline Maltose $10 \%$ & $3,894,098$ & 1.60 & 62 & 2.05 & 1.27 & $25.40 \pm 2.0$ & -37 & -59.29 \\
\hline Sucrose 1\% & $4,159,694$ & 0.242 & 47 & 2.90 & 1.36 & $27.26 \pm 1.9$ & -35.14 & -56.3 \\
\hline Sucrose $2 \%$ & $1,813,249$ & 0.405 & 57 & 1.044 & 0.59 & $11.90 \pm 0.9$ & -50.5 & -80.92 \\
\hline Sucrose $5 \%$ & $4,763,647$ & 1.028 & 87 & 1.792 & 1.55 & $31.18 \pm 2.0$ & -31.22 & -50.03 \\
\hline Sucrose $10 \%$ & $42,053,580$ & 1.635 & 44 & 31.46 & 13.84 & $276.80 \pm 8.7$ & 214.4 & 343.58 \\
\hline
\end{tabular}

Table 4. Effect of different nitrogen sources and their concentrations on the production of cyclosporin 'A' by Aspergillus terreus FCBP58.

\begin{tabular}{|c|c|c|c|c|c|c|c|c|}
\hline \multirow{2}{*}{ Treatment } & \multirow{2}{*}{ Peak area } & \multirow{2}{*}{\multicolumn{2}{|c|}{$\begin{array}{cc}\begin{array}{c}\text { Weight of dry } \\
\text { biomass }\end{array} & \begin{array}{c}\text { Weight of dry } \\
\text { extract }\end{array} \\
\end{array}$}} & \multicolumn{5}{|c|}{ Cyclosporin ' $A$ ' productivity } \\
\hline & & & & $\%$ & $\mathrm{mg} / 50 \mathrm{~mL}$ & $\mu \mathrm{g} / \mathrm{mL}$ & Increase/ & \%increase/de \\
\hline Casamino acids $0.5 \%$ & $16,364,563$ & 0.628 & 66 & 8.0 & 5.28 & $105.60 \pm 3.0$ & 43.2 & 69.2 \\
\hline Casamino acids $1.0 \%$ & $8,379,095$ & 0.595 & 42 & 6.56 & 2.75 & $55.0 \pm 2.7$ & -7.4 & -11.9 \\
\hline Casamino acids $2.0 \%$ & $7,232,184$ & 0.767 & 27 & 8.77 & 2.37 & $47.40 \pm 2.1$ & -15 & -24.0 \\
\hline Peptone $0.5 \%$ & $83,134,204$ & 0.69 & 66 & 40.95 & 27.0 & $540.0 \pm 8.1$ & 477.6 & 765.4 \\
\hline Peptone $1.0 \%$ & $9,701,506$ & 0.964 & 94 & 3.63 & 3.41 & $68.2 \pm 1.7$ & 5.8 & 9.29 \\
\hline Peptone $1.5 \%$ & $11,153,821$ & 1.595 & 113 & 3.25 & 3.67 & $73.40 \pm 2.0$ & 11 & 17.62 \\
\hline Peptone $2.0 \%$ & $8,809,388$ & 0.714 & 104 & 2.78 & 2.90 & $58.0 \pm 2.1$ & -4.4 & -7.05 \\
\hline Trypton $0.5 \%$ & $18,545,336$ & 0.542 & 78 & 7.68 & 5.99 & $119.80 \pm 5.4$ & 57.4 & 92.0 \\
\hline Trypton $1.0 \%$ & $16,458,531$ & 0.48 & 43 & 12.42 & 5.34 & $106.80 \pm 3.7$ & 44.4 & 71.1 \\
\hline Trypton $1.5 \%$ & $8,626,905$ & 0.585 & 21 & 13.5 & 2.83 & $56.60 \pm 1.9$ & -5.8 & -9.3 \\
\hline Trypton $2.0 \%$ & $12,679,379$ & 0.705 & 38 & 10.92 & 4.15 & $83.0 \pm 2.4$ & 20.6 & 33.0 \\
\hline Asparagine $0.1 \%$ & $9,542,019$ & 0.756 & 61 & 5.0 & 3.07 & $61.48 \pm 3.1$ & -0.92 & -1.5 \\
\hline Asparagine $0.2 \%$ & $10,616,702$ & 0.855 & 40 & 8.77 & 3.5 & $70.16 \pm 3.7$ & 7.76 & 12.43 \\
\hline Asparagine $0.4 \%$ & $9,223,835$ & 0.69 & 41 & 7.2 & 3.0 & $59.86 \pm 3.2$ & -2.54 & -4.1 \\
\hline Leucine $0.1 \%$ & $3,549,633$ & 0.55 & 52 & 2.22 & 1.15 & $23.0 \pm 1.8$ & -39.4 & -63.1 \\
\hline Leucine $0.2 \%$ & $2,883,930$ & 0.637 & 47 & 2.02 & 0.95 & $19.0 \pm 1.7$ & -43.4 & -69.6 \\
\hline Leucine $0.4 \%$ & $2,510,248$ & 0.678 & 53 & 1.57 & 0.83 & $16.64 \pm 1.5$ & -45.7 & -73.3 \\
\hline Leucine $0.6 \%$ & $1,278,554$ & 0.669 & 55 & 0.76 & 0.42 & $8.36 \pm 1.4$ & -54.0 & -86.6 \\
\hline Tyrosine $0.1 \%$ & $1,441,381$ & 0.778 & 41 & 1.14 & 0.47 & $9.34 \pm 1.5$ & -53.06 & -85.0 \\
\hline Tyrosine $0.2 \%$ & $2,397,367$ & 0.793 & 54 & 1.4 & 0.456 & $15.12 \pm 2.1$ & -47.28 & -75.76 \\
\hline Tyrosine $0.4 \%$ & $1,247,816$ & 0.994 & 45 & 0.924 & 0.415 & $8.30 \pm 0.9$ & -54.1 & -86.69 \\
\hline Tyrosine $0.6 \%$ & $1,700,814$ & 0.888 & 60 & 0.90 & 0.54 & $10.80 \pm 1.0$ & -51.6 & -82.69 \\
\hline Valine $0.1 \%$ & $14,193,755$ & 0.781 & 47 & 9.82 & 4.61 & $92.20 \pm 5.0$ & 29.8 & 47.75 \\
\hline Valine $0.2 \%$ & $5,316,042$ & 0.837 & 41 & 4.176 & 1.7 & $34.0 \pm 2.0$ & -28.4 & -45.51 \\
\hline Valine $0.4 \%$ & $12,729,486$ & 0.803 & 47 & 8.81 & 4.14 & $82.81 \pm 2.4$ & 20.41 & 32.70 \\
\hline Valine $0.6 \%$ & $7,493,167$ & 0.817 & 61 & 3.93 & 2.40 & $48.0 \pm 1.4$ & -14.4 & -23.07 \\
\hline
\end{tabular}


Trypton also enhanced the drug production by $92 \%$ and 71.1 $\%$ when used in 0.5 and $1 \%$ concentrations respectively. Although the percentage of enhancement was much lower to that of peptone, but this increase was observed at almost all the tested concentrations. Trypton is commonly used in microbiology to produce Lysogeny broth for the growth of microorganisms and provides a source of amino acids for the growing bacteria. Trypton is similar to casamino acids, both being digests of casein, but casamino acids can be produced by acid hydrolysis and typically only have free amino acids and few peptide chains. Casamino acids in concentration of $0.5 \%$ and $1.5 \%$ significantly increased cyclosporin 'A' production by $69.2 \%$ and $60.2 \%$ respectively when compared to the value recorded in unmodified production medium.

The fungal production of peptide and depsipeptide antibiotics may be directed and enhanced by amino acid components of the antibiotic molecule. Kobel and Traber (17) reported the direct synthesis of cyclosporin 'A' and several analogues in fermentations where the composition and titre of each analogue produced were strongly determined by the kind of externally supplemented amino acid. Accordingly, four amino acids asparagine, leucine, tyrosine and valine were tested for their drug enhancing effect. Valine showed enhancing effect on cyclosporin 'A' production, when used in 0.1 and $0.4 \%$ concentration (Fig. 5D). Similar results were obtained by Balakrishan and Pandey (3) when they found L-leucine and L-valine as strong inducers of cyclosporin 'A'. They also noticed that D-valine had no stimulatory effect on drug production. Also the presence of amino acids in the exponential growth phase ensured optimal production, as was indicated in an experiment, in which L-valine was added at different times.

However, in agreement with these workers, an increase in total cyclosporine production was seen, but of considerably higher magnitude. L-valine may have a role of inducer to increase the transcription of genes for cyclosporin 'A' synthetase or other structural genes contributing to cyclosporin 'A' synthesis in our fungal strain, given the positive effect of the amino acid when added early in the fermentation. Some amino acids may act as inducers which must be added in exponential growth phase to manifest their ability to enhance secondary metabolite production. It is also possible that these amino acids may direct cell development in a manner favouring secondary metabolite production by affecting transcription of secondary metabolite genes during vegetative cell growth (14).

The results showed that the modification of production medium by increasing glucose concentration to $10 \%$ as carbon source and addition of lower peptone concentration of $0.5 \%$ as nitrogen source along with valine $(0.1 \%)$ supplementation can significantly increase cyclosporin 'A' production.

\section{Drug production versus fungal biomass}

When increase in fungal biomass produced by selected strain in various modified media was compared to the increment of cyclosporin ' $A$ ' the drug production was not found directly associated with increase in biomass (Fig. 6-8). Similar results have been reported by earlier workers. Sallam et al. (28) reported that biomass yield and hence the volumetric production of cyclosporin ' $A$ ' increased linearly when they changed initial $\mathrm{pH}$ of the medium from 3.3 to 5.3 , however further increase in $\mathrm{pH}$ increased biomass of A. terreus but considerably decreased drug production. An exception was observed in case of glucose, when it supplied as a sole carbon source its increase in concentration increased biomass of $A$. terreus and so the drug production.

\section{Drug production versus extract colour}

The colour of the final extract containing cyclosporins showed variation from light yellow to dark reddish orange. However, the darkness of colour also did not seem to correspond with any increment in amount of cyclosporin ' $A$ '. In case of glucose, increase in sugar concentration in production medium increased drug production and also the colour intensity. It is supposed that the final extract is a combination of various cyclosporins and may posses some other compounds. The quantity of these compounds also varies with variation in the treatments. This can affect the colour of final extract that do not directly relates to the increase in cyclosporin ' $A$ ' production. 


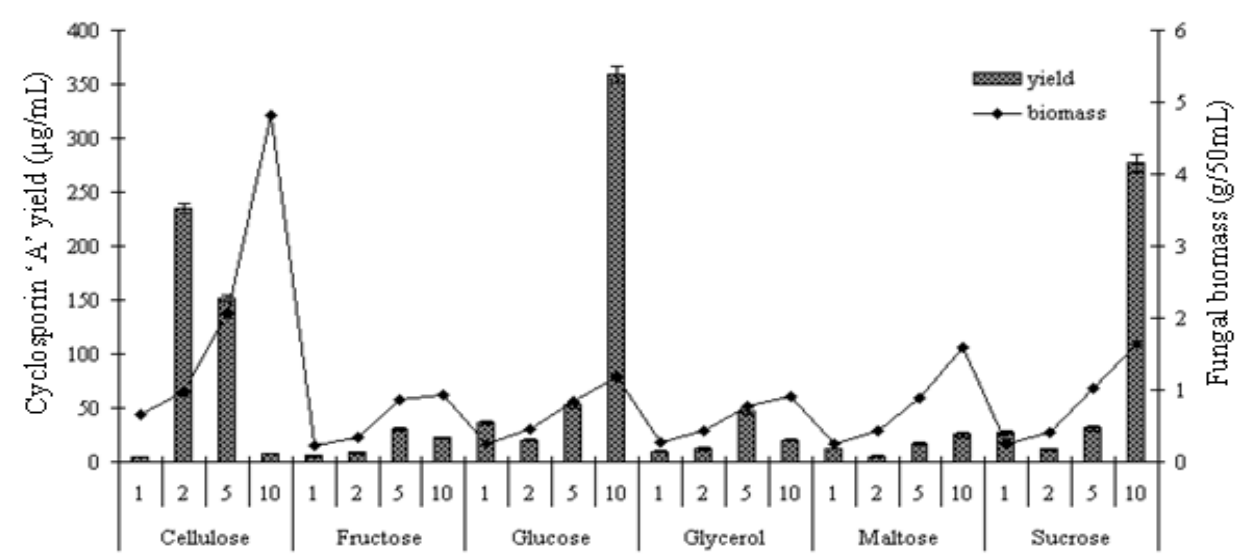

Carbon source concentration (\%)

Figure 6. Effect of different carbon sources and their concentrations on production of cyclosporin ' $A$ ' and fungal biomass in production medium (values are mean $\pm \mathrm{SE}$ of 3 observations).

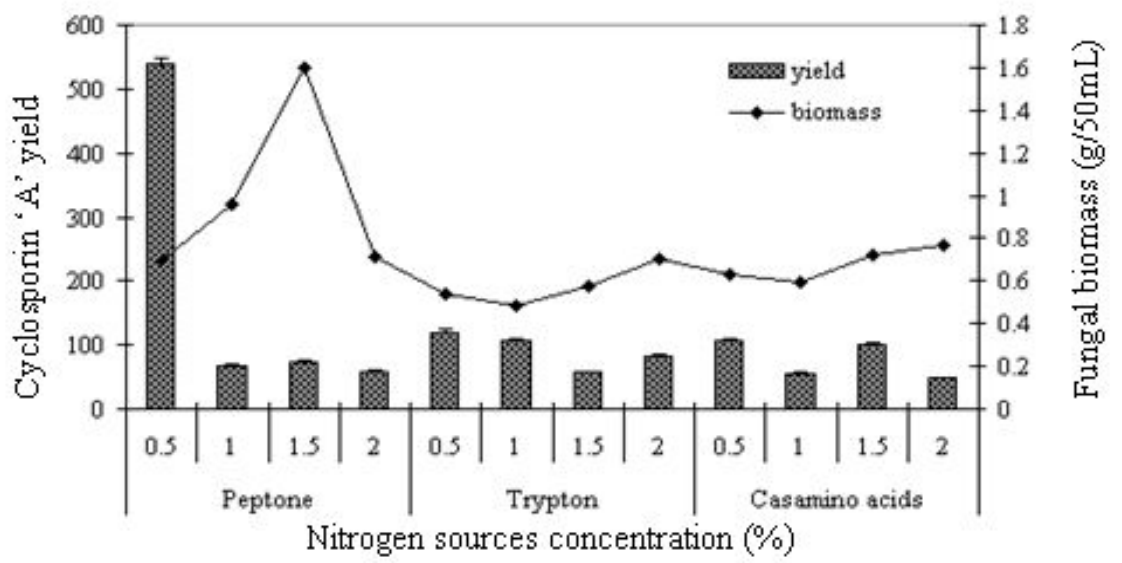

Figure 7. Effect of different nitrogen sources and their concentrations on production of cyclosporin 'A' and fungal biomass in production medium (values are mean $\pm \mathrm{SE}$ of 3 observations).

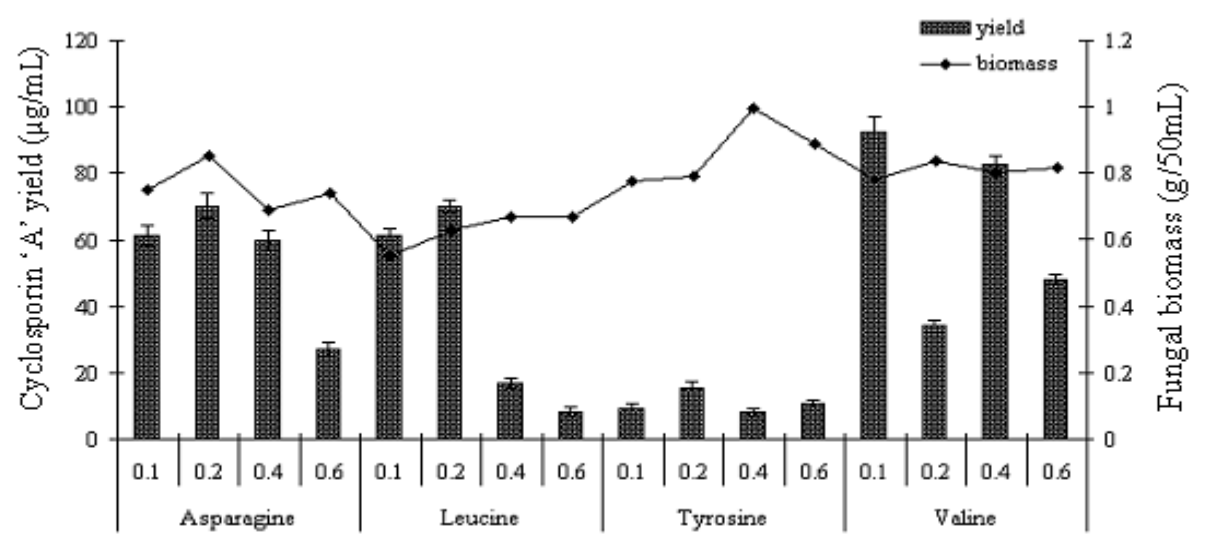

Amino acid concentration (\%)

Figure 8. Effect of different amino acids and their concentrations on production of cyclosporin 'A' and fungal biomass in production medium (values are mean \pm SE of 3 observations). 


\section{REFERENCES}

1. Agathos, S.N.; Lee, J. (1993). Mathematical modelling of the production of cyclosporin A by Tolypocladium inflatum: Effect of L-valine. Biotechnol. Prog. 9(1):54-63.

2. Agathos, S.N.; Marshall, J.W.; Moraiti, C.; Parekh, R.; Madhosingh, C. (1986). Physiological and genetic factors for process development of cyclosporine fermentations. J Ind. Microbiol. 1:39-48.

3. Balakrishnan, K.; Pandey, A. (1996). Influence of amino acids on the biosynthesis of cyclosporin A by Tolypocladium inflatum. Appl. Microbiol. Biotechnol. 45:800-803.

4. Balaraman, K.; Mathew, N. (2006). Optimization of media composition for the production of cyclosporin A by Tolypocladium species. Indian J Med. Res. 123:525-530.

5. Billich, A.; Zocher, R. (1987). Enzymatic synthesis of cyclosporin A. J Biol. Chem. 262:17258-17259.

6. Bok, J.W.; Keller, N.P. (2004). LaeA, a regulator of secondary metabolism in Aspergillus spp. Eukaryotic cell. 3(2):527-535.

7. Borel, J.F.; Feurer, C.; Magnee, C.; Stahelin, H,. (1977). Effects of the new anti-lymphocytic peptide cyclosporin A in animals. Immunology. 32:1017-1025

8. Borel, J.F. (1986). Cyclosporin and its future. Prog. Allergy. 38:9-18.

9. Chun, G.T.; Agathos, S.N. (1989). Immobilization of Tolypocladium inflatum spores into porous celite beads for cyclosporin A production. J Biotechnol. 9:237-254.

10. Chun, G.T.; Agathos, S.N. (1993). Dynamic response of immobilized cells to pulse addition of L-valine in cyclosporin A biosynthesis. J Biotechnol. 27(3):283-294.

11. Derks, R.M.P.; Madris, S.M. (2001). The Aspergillus niger Cyp A gene encodes a cyclophilin that mediates sensitivity to the immunosuppressant cyclosporine A. Genet. Genomic. 206:527-536.

12. Dreyfuss, M.; Härri, E.; Hofmann, H.; Kobel, H.; Pache, W.; Tscherter, H. (1976). Cyclosporin A and C. New metabolites from Trichoderma polysporum. Eur. J Appl. Microbiol. 3:125-133.

13. El-Refai, H.A.; Abd-Elsallam, I.S.; Sallam, L.A. (2004). Kinetic studies on the growth and cyclosporin A production by a local isolate of Fusarium oxysporum, NRC. Acta pharmaceut. turcica., 46:197-204.

14. Gräfe, U. (1982). In: Overproduction of Microbial Products. Eds. Krumphanzl V, Sikyta B and Vanek Z. Academic Press, New York. pp 63-75.

15. Isaac, C.E.; Jones, A.; Pickard, M.A. (1990). Production of cyclosporins by Tolypocladium niveum strains. Antimicrob. Agents Chemother. 34(1):121-127.

16. Kannan, N.D.; Kalaichelvan, P.T. (2007). Production of immunosuppressant drug cyclosporin A from Tolypocladium inflatum in presence of L-valine. Allelopath. J. 19(2): Print ISSN: 0971-4693. Online ISSN : 0973-5046.

17. Koble, H..; Traber, R. (1982). Directed biosynthesis of cyclosporins. Eur. J Appl. Microbiol. Biotechnol. 14:237-240.

18. Lawen, A.; Traber, R.; Geyl, D.; Zocher, R.; Kleinkauf, H. (1989). Cellfree biosynthesis of new cyclosporins. J. Antibiot. 42:1283-1289.

19. Lee, J.; Agathos, S.N. (1989). Effect of amino acids on the production of cyclosporin A by Tolypocladium inflatum. Biotechnol. Letters. 11(2):7782.

20. Lee, J.; Agathos, S.N. (1991). Dynamic of L-valine in relation to the production of cyclosporin A by Tolypocladium inflatum. Appl. Microbiol. Biotechnol. 34: 513-517.

21. Lee, M.J.; Lee, H.N.; Han, K.; Kim, E.S. (2008). Spore inoculum optimization to maximize cyclosporin A production in Tolypocladium niveum. J. Microbiol. Biotechnol. 18(5):913-917.

22. Lee, T.H.; Chun, G.T.; Chang, Y.K. (1997). Development of sporulation/immobilization method and its application for the continuous production of cyclosporin A by Tolypocladium inflatum. Biotechnol. Prog. 13:546-550.

23. Minutza, L.; Itamar, K.; Michael, F. (2009). Pharmaceutical composition comprising candesartan cilexetil. US Patent 0048316. USA, Pharmatec International S.R.L.

24. Nakajima, H.; Hamasaki, T.; Nishimura, K.; Kondo, T.; Kimura, Y.; Udagawa, S. (1988). Isolation of 2-acetylamino-3- hydroxy-4-methyloct6-enoic acid, a derivative of the "C9-amino acid" residue of cyclosporins, produced by the fungus Neocosmospora vasinfecta. Agric. BioL Chern. $52(6): 1621-1623$.

25. Ramachandran, M.M.; Balakrishnan, K.; Cynthiya, A.D.; Sankar, M.; Panimalar, M.; Karthikeyan, G.S.R. (2006). Screening and isolation of cyclosporine-related compound producing soil fungi from the Western Ghats, Tamil Nadu. Curr. Scien. 92,6-25.

26. Sawai, K.; Okuno, T.; Tereda, Y.; Harada, Y.; Wawamura, K.; Sasaki, H.; Takao, S. (1981). Isolation and properties of two antifungal substances from Fusarium solani. Agric. Biol. Chem. 45(5):1223-1228.

27. Sallam, L.A.R.; El-Refai, A.H.; Hamdi, A.A.; El-Minofi, A.H.; AbdElsalam, S.I. (2005). Studies on the application of immobilization technique for the production of cyclosporin A by a local strain of Aspergillus terreus. J Gen. Appl. Microbiol. 51(03):143-149.

28. Sallam, L.A.R.; El-Refai, A.M.H.; Hamdy, A.H.A.; El-Minofi, H.A.; Abdel-Salam, I.S. (2003). Role of some fermentation parameters on cyclosporin A production by a new isolate of Aspergillus terreus. J Gen. Appl. Microbiol. 49:321-328.

29. Vieira, G.R.T.; Liebl, M.; Tavares, L.B.B.; Paulert, R.; Smania, A. (2008). Submerged culture conditions for the production of mycelial biomass and antimicrobial metabolites by Polyporus tricholoma. Brazilian J. Microbiol. 39(3): 561-568. 